\title{
Long-term Trial of Disodium Cromoglycate and Isoprenaline in Children with Asthma
}

\author{
M. SILVERMAN, NICOLA M. CONNOLLY, L. BALFOUR-LYNN, S. GODFREY
}

British Medical fournal, 1972, 3, 378-381

\section{Summary}

A year-long double-blind trial was carried out in 53 asthmatic children with severe perennial symptoms who were not receiving corticosteroids or corticotrophin. The treatment group were given disodium cromoglycate with isoprenaline (Intal Co.) while the placebo group were given lactose with isoprenaline four times daily. The groups were closely matched for clinical, physiological, and immunological features. Evaluation was based on the use of a diary and clinical and physiological investigations, including exercise tests.

After one year $71^{\prime \prime} \%$ of the treatment group were still well controlled while $76^{\circ}$, of the placebo group had dropped out because of inadequate control of symptoms. There was no rise in the rate of failure towards the end of the trial period and there were no seasonal variations in the failure rate. No important toxic effects were noted. It was impossible to predict the outcome of the trial in any given patient from his clinical, physiological, or immunological status at the beginning. However, the prevention of exercise-induced asthma by premedication with disodium cromoglycate in a laboratory exercise test did correlate well with the satisfactory clinical response to the drug.

\section{Introduction}

It has been shown by a number of workers that disodium cromoglycate (D.S.C.G.) is of value in the management of bronchial asthma (Howell and Altounyan, 1967; Morrison Smith and Devey, 1968; Kennedy, 1969; Robertson, Epstein, and Warrell, 1969; Jones and Blackhall, 1970; Toogood, Lefcoe, Rose, and McCourtie, 1971).

One of the difficulties in the objective assessment of the response to drugs of asthmatic subjects is that because of the extreme variability of the disease from day to day spirometric and other physiological measurements made only occasionally during the course of treatment may remain unchanged in spite of a real improvement in clinical condition (Falliers, McCawn, Ellis, and Chai, 1966; Chai, Purcell, Brady, and Falliers, 1968; Robertson et al., 1969). Another problem in the long-term assessment of children with asthma is the spontaneous improvement in clinical condition which can be expected even in the course of one year (Williams and McNicol, 1969). This means that open or uncontrolled long-term trials in children may produce spurious results, especially if intermittent physiological tests are used to assess the response to treatment. Likewise, without adequate control the appearance of tolerance to a drug, manifest by a recurrence of symptoms after a period of remission, might be difficult to detect.

\footnotetext{
Department of Paediatrics, Institute of Diseases of the Chest, London S.W.3

M. SILVERMAN, M.B., M.R.C.P., Clinical Lecturer

NICOLA M. CONNOLLY, M.B., D.C.H., Clinical Lecturer

NICOLA M. CONNOLLY, M.B., D.C.H., Clinical Lect
L. BALFOUR-LYNN, M.B., D.C.H., Clinical Assistant

L. BALFOUR-LYNN, M.B., D.C.H., Clinical As

With the help of TINA ANDREA, Technician
}

For these reasons a long-term double-blind trial of D.S.C.G. in children with severe asthma was carried out with the use of objective and subjective methods of assessment to measure differences between treatment regimens.

\section{Subjects and Protocol}

Sixty-two children from the paediatric outpatient clinic of the Brompton Hospital, all with asthma as defined by Scadding (1966), were originally admitted to the trial having met the following criteria: (1) they had perennial asthma and disability exceeding six to eight weeks in the preceding year or three to four weeks in the preceding three months in spite of regular bronchodilator treatment; (2) none had ever taken D.S.C.G., corticosteroid drugs, or corticotrophin; (3) they and their parents were willing and able to co-operate with the investigations. The children were randomly assigned in a double-blind fashion to the treatment (D.S.C.G.) or the placebo group. Initially each patient was examined and a detailed history, family history, and account of previous drug use recorded. A chest $x$-ray examination was carried out as well as modified prick-testing with a range of 22 common antigens, white blood cell count, eosinophil count, and serum transaminase and urea estimations.

The treatment group received capsules consisting of D.S.C.G. $20 \mathrm{mg}$, lactose $20 \mathrm{mg}$, and isoprenaline $0.1 \mathrm{mg}$, while the placebo group received capsules containing lactose $35 \mathrm{mg}$, sodium sulphate $5 \mathrm{mg}$, and isoprenaline $0.1 \mathrm{mg}$. At the time that this trial was begun it had been suggested that D.S.C.G. should be combined with isoprenaline to avoid possible bronchoconstriction. It was also thought undesirable to give asthmatic children lactose alone as a placebo, and thus the combined capsules were employed.

Having fulfilled the entry criteria and performed the baseline tests each child was given a two-week supply of practise capsules (identical with placebo capsules) to be taken twice daily along with other drugs which were thought necessary. Daily records of symptoms were kept during this run-up period by use of the diary described by Connolly and Godfrey (1970), and a Wright peak-flow meter was provided for use at home. Each child was instructed to record the best of three blows into the meter morning and evening before taking any drugs and to record this as the peak expiratory flow rate (PEFR).

The 52-week trial period succeeded the run-up period without a break, the patients taking their allotted trial capsules four times daily. They were also allowed such bronchodilators (oral orciprenaline or salbutamol) and antihistamines (promethazine) as were necessary to relieve symptoms.

During the first four weeks of the trial PEFR recordings were again made twice daily at home. At each four-weekly visit the following were recorded: daily record scores for the previous four weeks, spirometry, PEFR, height, weight, and subjective assessment of overall clinical condition by the parent and the physician using an arbitrary 100-point scale. At less frequent intervals exercise tests to measure bronchial lability were performed (Connolly and Godfrey, 1970), and an index of bronchial lability was calculated after the style of Jones (1966).

Predicted values for PEFR were taken from Godfrey, Kamburoff, and Nairn (1970). Histamine challenge tests were performed by the inhalation of 0.1 to $0.3 \%$ histamine acid phosphate solution for two minutes from a Wright nebulizer, forced expiratory volume in one second $\left(F E V V_{1}\right)$ being measured 
before and serially after the inhalation. At the end of the trial chest $x$-ray examination and skin tests were repeated.

\section{CRITERIA OF FAILURE}

Treatment was regarded as having failed and the drug code was broken if either $(a)$ the diary score over the previous four weeks exceeded the diary score for the run-up period by a mean of more than four points a day (out of a possible 13 points a day) or the daily diary score exceeded 10 points on more than seven days or 11 points on more than four days; or (b) the physician decided that recent history, excessive bronchodilator drug usage, or physical examination demanded a change of treatment; the reliability of the daily record and of the witnesses was taken into account.

When a child's code had been broken he progressed automatically from the placebo group to a group receiving capsules of D.S.C.G. (plus isoprenaline), or from the treatment (D.S.C.G.) group to a group receiving corticosteroids.

\section{Results}

A total of 53 patients completed the trial out of the 62 originally admitted; 24 were in the treatment group and 29 in the placebo group. There was no significant difference between the two groups at the start of the trial in terms of sex, age, duration and severity of asthma, family history, evidence of allergy, spirometry, lability index, or histamine sensitivity (Table I). Of the nine

TABLE I-Characteristics of the Treatment and Placebo Groups

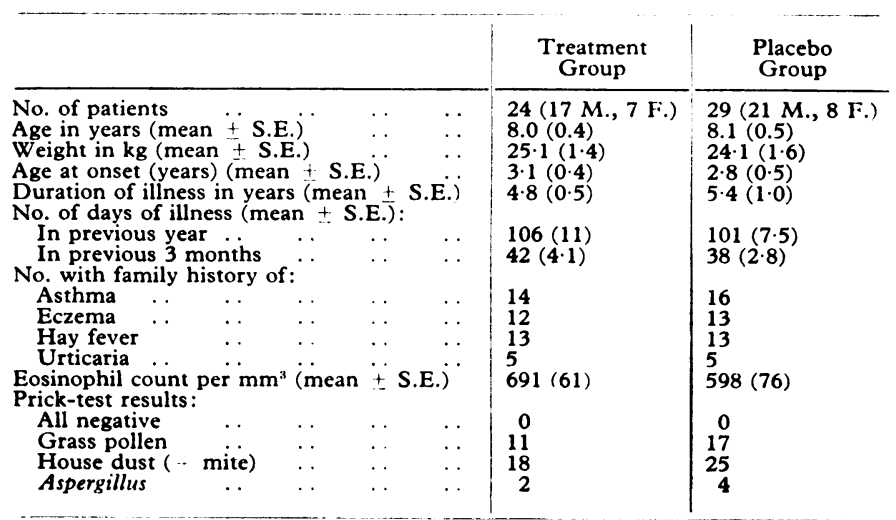

patients who dropped out six failed to attend regularly or to keep daily record cards, two emigrated, and one who was in the treatment group felt so well that he decided not to continue with the trial.

A clear difference was found in the failure rates of the two groups (Fig. 1). Whereas $22(76 \%)$ of the 29 in the placebo group failed, only $7(29 \%)$ of the 24 in the active group did so. This difference is highly significant $\left(\varkappa^{2}=12.9, P<0.001\right)$. In almost all cases the reasons for failure were multiple, including high diary score, low mother's score, and poor spirometry. In both the treatment and placebo groups failure tended to occur in the first 24 weeks; the failure rate in the treatment group did not increase towards the end of the trial (Fig. 1), suggesting that the efficacy of the drug did not diminish with time. Failures occurred in each group throughout the year and no seasonal variations were noted.

By using discriminant function analysis on the pretrial data of patients who succeeded or failed on D.S.C.G., it was found impossible to predict the outcome of the trial on the basis of age, sex, duration and severity of asthma, initial spirometry,

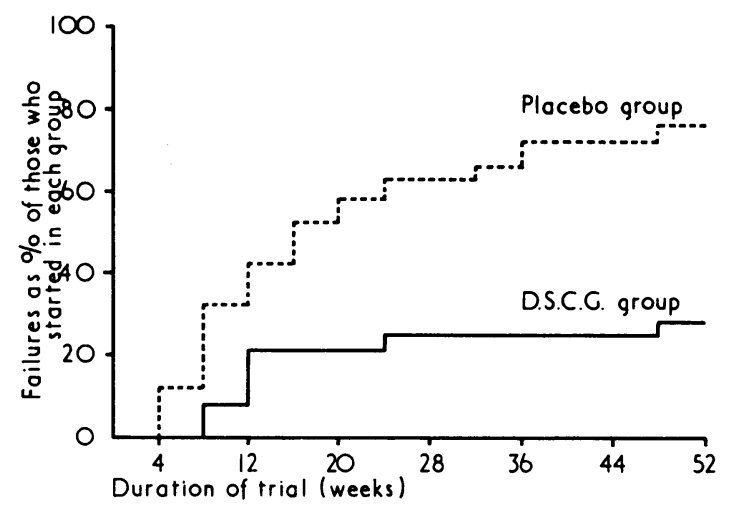

FIG. 1-Pattern of clinical failure in the two patient groups over period of trial.

or lability index. Nor were there any significant differences in the frequency of prick-test responses to various allergens (including the house-dust mite, grass pollen, and Aspergillus fumigatus), the total white cell count or eosinophil count, or in the incidence of a positive family history of asthma between the successes and failures of D.S.C.G. therapy.

Only the results of the laboratory assessments of the efficacy of D.S.C.G. by means of exercise tests were of value in the prediction of the probable success or failure of long-term treatment with the drug. A total of nine patients in whom treatment with D.S.C.G. proved unsatisfactory were studied; seven were from the initial treatment (D.S.C.G.) group, while two had at first been in the placebo group but had progressed to D.S.C.G. treatment, which later also proved unsatisfactory. Ten patients whose response to D.S.C.G. was good were also studied. In both the D.S.C.G. success group and the D.S.C.G. failure group the drug had a significant ameliorating effect on exerciseinduced asthma (Table II). However, while eight of the 10 patients in the success group showed changes in PEFR after

TABLE II-Exercise Tests performed with and without Premedication with D.S.C.G. in Subjects who Responded Clinically to the Drug and Those who Failed

\begin{tabular}{|c|c|c|c|c|}
\hline & \multicolumn{2}{|c|}{$\begin{array}{l}\text { Clinical D.S.C.G. } \\
\text { Failure }(\mathrm{n} \cdots 9)\end{array}$} & \multicolumn{2}{|c|}{$\begin{array}{l}\text { Clinical D.S.C.G. } \\
\text { Success }(n=10)\end{array}$} \\
\hline & $\begin{array}{l}\text { Without } \\
\text { Premed. }\end{array}$ & $\begin{array}{l}\text { With } \\
\text { Premed. }\end{array}$ & $\begin{array}{l}\text { Without } \\
\text { Premed. }\end{array}$ & $\begin{array}{c}\text { With } \\
\text { Premed. }\end{array}$ \\
\hline $\begin{array}{l}\text { Initial PEFR as ". predicted } \pm \\
\text { S.E. } 0 . \\
\text { Fall in PEFR after exercise as } \\
\text { of resting value } \pm \text { S.E. }\end{array}$ & $\begin{array}{l}69 \pm 6 \\
45+4\end{array}$ & $\begin{array}{l}66 \pm 7 \\
18+5\end{array}$ & $\begin{array}{l}83 \pm 7 \\
42 \pm 6\end{array}$ & $\begin{array}{r}83 \pm 6 \\
9 \pm 4\end{array}$ \\
\hline $\begin{array}{l}\text { No. of subjects with suppression } \\
\text { of exercise-induced asthma by } \\
\text { D.S.C.G. }\end{array}$ & \multicolumn{2}{|c|}{$2^{*}$} & \multicolumn{2}{|c|}{8} \\
\hline
\end{tabular}

*One other subject responded transiently (see text).

exercise which were within normal limits after premedication with D.S.C.G., only three of the nine in the failure group did so. This difference is significant $\left(\gamma^{2}=4.23, P<0.05\right)$. It was later shown for one of the three clinical failures who apparently derived benefit from D.S.C.G. given before exercise that the duration of this effect was brief (less than two hours). The other two were not examined in this way but it is hoped to do so as part of another study.

During the first four to eight weeks of the trial the treatment and placebo groups were not significantly depleted by failures dropping out, and it was therefore possible to compare the results of a number of investigations carried out during that time (Table III). Non-parametric statistical tests were used for assessment. 
TABLE III-Short-term Changes in the Ti'o Patient Groups over the First TABLE III-Short-term to Eight Weeks of Trial
Four

\begin{tabular}{|c|c|c|c|c|}
\hline & & \multicolumn{2}{|c|}{ Significant Improvement } & \multirow{2}{*}{$\begin{array}{l}\text { Group with } \\
\text { Significantly } \\
\text { Greater } \\
\text { Improvement }\end{array}$} \\
\hline & & D.S.C.G. & Placebo & \\
\hline $\begin{array}{l}\text { Diary score .. } \\
\text { Daily PEFR: } \\
\text { Morning . . } \\
\text { Evening . . } \\
\text { Mean } \\
\text { Monthly PEFR } \\
\text { Monthly FEV } \\
\text { Monthly FVC } \\
\text { Lability index: } \\
\text { Exercise . } \\
\text { Histamine } \\
\text { Eosinophilia ... } \\
\text { Blood urea ... } \\
\text { Subjective tests : } \\
\text { Mother's score } \\
\text { Physician's score }\end{array}$ & $\begin{array}{l}\cdots \\
\cdots \\
\cdots \\
\cdots \\
\cdots \\
\cdots \\
\cdots \\
\cdots \\
\cdots \\
\cdots \\
\cdots\end{array}$ & $\begin{array}{l}\mathrm{P}<0.001 \\
0.01>\mathrm{P}>0.001 \\
0.01>\mathrm{P}>0.001 \\
0.01>\mathrm{P}>0.001 \\
0.05>\mathrm{P}>0.01 \\
\text { N.S. }>\mathrm{P}>0.01 \\
0.05> \\
\text { N.S. } \\
\text { N.S. } \\
\text { N.S. } \\
+ \\
0.01>\mathrm{P}>0.001 \\
0.01>\mathrm{P}>0.001\end{array}$ & $\begin{array}{l}P<0.001 \\
\text { N.S. } \\
\text { N.S. } \\
\text { N.S. } \\
0.01>P>0.001 \\
\text { N.S. } \\
\text { N.S. } \\
\text { N.S. } \\
\text { N.S. } \\
\text { N.S. } \\
\text { N.S. } \\
\text { 0.01 }>\mathrm{P}>0.001 \\
0.01>\mathrm{P}>0.001\end{array}$ & $\begin{array}{l}\text { D.S.C.G. } \\
\text { D.S.C.G. } \\
\text { D.S.C.G. } \\
\text { D.S.C.G. } \\
\text { N.S. } \\
\text { N.S. } \\
\text { N.S. } \\
\text { N.S. } \\
\text { N.S. } \\
\text { N.S. } \\
\text { N.S. } \\
\text { D.S.C.G. } \\
\text { N.S. }\end{array}$ \\
\hline
\end{tabular}

*Detailed results will be supplied on request

+Significant rise but all values within normal limits at all times. N.S. = Not significant $(P>0.05)$

FVC $=$ Forced vital capacity.

In both groups the diary score improved significantly compared with the pretrial level, but the improvement was greater for the D.S.C.G. group, especially for night-time disturbance and cough. Even patients who ultimately failed in both treatment and placebo groups had some improvement in diary score, but it was not so pronounced as in the successes (Fig. 2). By contrast the mean daily PEFR improved only in the treatment group, and this was due to improvement in both morning and evening readings as well as in a smaller diurnal swing. Random PEFR or spirometry measured at monthly intervals showed no difference between the two groups, the true improvement shown by the daily readings having been lost in the random variation.

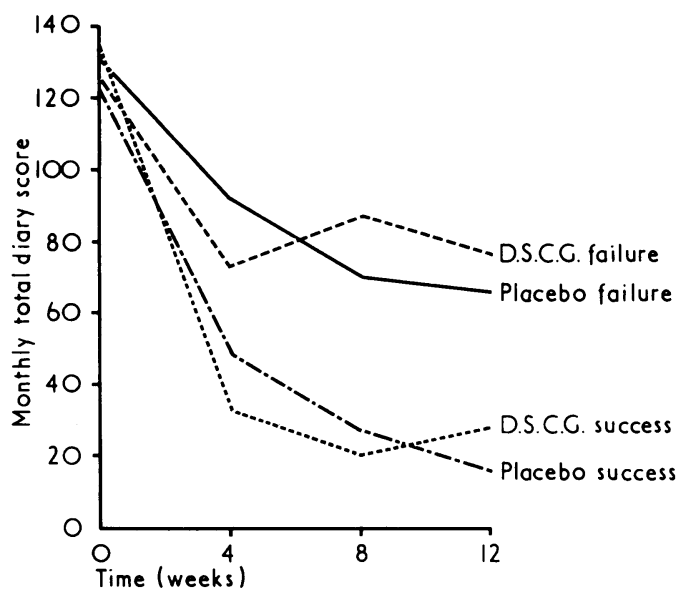
FIG. 2-Mean diary scores at monthly intervals for first
three months in the D.S.C.G. and placebo groups divided into treatment failures and successes.

There was no significant change in bronchial lability tested with exercise or with histamine in either group, nor was there any change in eosinophil count or blood urea.

Subjective assessment by both mother and physician indicated improvement in both the treatment and placebo groups over these first two months, but the mothers indicated significantly greater improvement in the D.S.C.G. group.

No toxic effects were seen in any patient during the whole trial. Measurements of blood urea, serum alanine aminotransferase, and white blood cell counts as well as urine analysis for protein and reducing sugars all remained within normal limits. Transient dryness of the throat tending to provoke brief bouts of cough was the only occasional side-effect.

\section{Discussion}

This trial has shown that D.S.C.G. is highly effective in the long-term management of childhood asthma. Altogether $71 \%$ of asthmatic children were well controlled on the drug compared with only $24 \%$ in the placebo group. This means that $24 \%$ of asthmatic children whose illness could be called severe responded adequately to regular inhalation of $0.1 \mathrm{mg}$ of isoprenaline four times daily, or that some of them may have tended to grow out of their disease in the course of 12 months. Allowing for this response in the placebo group about $50 \%$ of the severe asthmatics required and benefited from regular treatment with D.S.C.G. This is close to the estimate arrived at by Jones and Blackhall (1970) in an open trial of the drug based on parent's statements, severity of illness, number of attacks, and physical signs. Morrison Smith and Devey (1968), in a two-month double-blind cross-over trial on 44 children, also claimed a $54 \%$ improvement rate with D.S.C.G. compared with $14 \%$ on placebo. The main method of assessment was the daily recording of an asthma disability score somewhat similar to the daily record used in the present study. The use of bronchodilator aerosols was significantly reduced in the D.S.C.G. group, but weekly recordings of spirometry showed little or no difference between groups. This is explained by the variability in random measurements found in the present study.

None of the characteristics of the patients measured before the start of the present trial provided a means of predicting who would do well and who would fail on treatment with D.S.C.G. Exercise tests performed later in the trial with and without premedication with the drug provided the only clue to the likely outcome. Great care is required in performing exercise tests, and the interval between successive tests should be kept as short as possible (Silverman and Anderson, 1972). Their predictive value may be expected to increase if tests are performed on successive days, a placebo being compared with the active drug.

The short-term analysis of the present trial (Table II) points out some of the difficulties inherent in the assessment of asthma. Of the objective (physiological) measurements twice-daily PEFR recordings by patients themselves in their own homes provided the best discrimination between treatment and placebo groups, confirming the work of Robertson et al. (1969), whereas monthly spirometry was irrelevant, as noted by Chen, Moore, Norman, Van Metre, and Baltimore (1969). The explanation neatly illustrated by Falliers et al. (1966) is that occasional measurements of lung function cannot accurately represent a condition as changeable as asthma. The objective measurements of bronchial lability by exercise testing or histamine challenge did not change during the course of the trial, which suggests that there was no persistant or "carry-over" effect on lung function beyond the normal duration of action of the drug, even after four to eight weeks of continuous treatment.

The daily recording of symptom scores on record cards, while not being objective, did give a means of assessment which differentiated the treatment and placebo groups. The daily record card seemed to commend itself to more general use since it provided the cheapest and one of the more reliable methods of assessment which were used in the present study. Not only was it possible to assess overall control of the illness but the effect of treatment on specific symptoms could also be evaluated. Thus the present study showed that D.S.C.G. had an appreciable effect on both cough and night-time symptoms as well as on the overall clinical condition.

Of least discriminant value were the subjective assessments provided by the parent and physician. Even in a double-blind trial, with the assistance of daily record, spirometry, and clinical examination of the patient, the two physicians who were responsible for almost all of the monthly assessments throughout 
the trial were unable to discriminate between treatment and placebo groups after four to eight weeks of treatment. That this was not due to a high incidence of placebo reactors is shown by the analysis of the objective tests-for example, daily PEFR recordings-and by the final outcome of the trial. It may, however, be a reflection of subjective improvements registered by the moderate initial decrease in daily record scores even in those subjects who later failed (Fig. 2). The failure of the physicians to approach objectivity even in a double-blind trial is not easy to explain, but may reflect the undue attention which is paid by physicians to the patient's (or parent's) history and a desire to give the current treatment regimen the "benefit of the doubt." It shows clearly that open assessment trials in asthma should be interpreted with great caution. Unfortunately, open assessment seems to have been the format of previous long-term clinical trials of D.S.C.G. which have been carried out with asthmatic children. Success rates varying from 38 to $100^{\circ}$, have been claimed.

It is concluded from the present study that D.S.C.G. alone can provide worth-while treatment for $50^{\circ}{ }_{\circ}^{\prime}$ of severe asthmatic children who would otherwise undoubtedly have needed corticosteroid therapy, in the absence of any important side- effects and with no evidence of tolerance over the first 12 months of treatment. A further $21 \%$ may be expected to remit over the course of one year with bronchodilator therapy alone.

\section{References}

Chai, H., Purcell, K., Brady, K., and Falliers, C. J. (1968). Gournal of Allergy, 41, 23.

Chen, L. J., Moore, N., Norman, P. S., Van Metre, T. E., and Baltimore, M. D. (1969). fournal of Allergy, 43, 89.

Connolly, N., and Godfrey, S. (1970). Fournal of Asthma Research, 8, 31.

Falliers, C. J., McCawn, W. P., Ellis, E. F., and Chai, H. (1966). Fournal of Allergy, 37, 1 .

Godfrey, S., Kamburoff, P., and Nairn, J. (1970). British fournal of Diseases

of the Chest, 64, 15.
Howell, J. B. L., and Altounyan, R. E. C. (1967). Lancet, 2, 539.

Jones, R. S. (1966). British Medical fournal, 2, 972.

Jones, R. S., and Blackhall, M. I. (1970). Archives of Disease in Childhood, 45,49 .

Kennedy, M. C. S. (1969). British Fournal of Diseases of the Chest, 63, 96.

Robertson, D. G., Epstein, S. W., and Warrell, D. A. (1969). British Medical fournal, $\mathrm{i}, 552$.

Scadding, J. G. (1966). Lancet, 1, 701.

Silverman, M., and Anderson, S. D. (1972). Archives of Disease in Childhood. In press.

Smith, J. M., and Devey, G. F. (1968). British Medical fournal, 2, 340.

Toogood, J. H., Lefcoe, N. M., Rose, D. K., and McCourtie, D. R. (1971). American Review of Respiratory Diseases, $104,323$.

Williams, H., and McNicol, K. N. (1969). British Medical fournal, 4, 321.

\title{
Implementation of the Abortion Act: Report on a Year's Working of Abortion Clinics and Operating Sessions
}

\author{
A. E. R. BUCKLE, MARY M. ANDERSON
}

British Miedical fournal, 1972, 3, 381-384

\section{Summary}

The results of the first year's working of abortion clinics and operating sessions are reported. Seventy-eight per cent. of patients were managed on the basis of day admission and $20^{\circ}$, were able to leave the hospital within four hours, operation having been carried out by either Karman catheter or by Bierer suction curette under paracervical block. These results were possible because of quick reference of patients to the clinics and the absence of delay in admission for operation.

The measures detailed go some way towards managing the abortion problem within the hospital service; similar arrangements could be instituted elsewhere by the responsible regional hospital boards.

\section{Introduction}

The introduction of the Abortion Act 1967 was not accompanied by the provision of extra facilities for its implementation. The expected rise in requests for abortion which followed quickly led to congestion of gynaecological clinics, an increase in waiting time for outpatient appointments, and difficulties with accommodation of cases, both in the wards and on routine operating lists. Although in theory there is no need to separate abortion referrals from other gynaecological appointments in practice there is much to commend this as it is easier for the gynaecologist to concentrate on similar problems throughout one session

Department of Obstetrics and Gynaecology, Lewisham General Hospital, London S.E.13

A. E. R. BUCKLE, F.R.C.s., F.R.c.o.G., Consultant

MARY M. ANDERSON, M.R.C.o.G., Consultant rather than to have them recurring between other referrals. In addition there is special need to deal with these cases as soon as practicable so that operation can, if possible, be carried out by the vaginal route. Similarly if patients are confined to operating lists set aside for abortions only it becomes easier to manage them from both nursing and medical points of view.

Bearing this in mind, and with the object of minimizing the additional strain which had been placed on the medical and nursing personnel of one specialty, we decided to reconsider the whole question of management of abortion referrals in our group. We suggested to our regional hospital board that abortion clinics should be set up and that abortion operating sessions should be arranged. After discussion it was agreed that two abortion clinics should be held weekly, these to be staffed by consultant gynaecologists, and that there should be one operating session weekly to be shared by two consultant gynaecologists, with a consultant anaesthetist in attendance. Furthermore, the board agreed to additional nursing establishment to allow for cover for the clinics, the operating theatres, and in the wards. The last mentioned was of particular importance, for most of the patients are dealt with as day admissions and this places a strain on general gynaecological wards. It has to date been impossible for us to set up a day case unit, and we have therefore been forced to use sections of the main wards set aside specifically for the purpose of day admission, as outlined below.

Despite these difficulties the patients have been accommodated, much credit going to the unfailing good will and forbearance of the nursing staff of the wards and the operating theatres, who have been prepared to make the scheme work smoothly.

It is with the results from the first year's working of these clinics and operating sessions that this paper is concerned.

\section{Clinics}

These are held twice weekly in the hospital antenatal clinic in the early evening. Patients who are referred for possible abortion 